\title{
Activated Charcoal Decreases Plasma Bilirubin Levels in the Hyperbilirubinemic Rat
}

\author{
DAVID R. DAVIS, ${ }^{(22)}$ ROGER A. YEARY, AND KYONG LEE \\ Department of Veterinary Physiology and Pharmacology, The Ohio State University, Columbus, Ohio, USA
}

\begin{abstract}
Summary
The effectiveness of phototherapy and activated charcoal feeding for reducing plasma bilirubin concentrations was studied in the hyperbilirubinemic Gunn rat. The feeding of charcoal alone was just as effective in reducing plasma bilirubin concentrations as continuous phototherapy. An additive effect on reducing plasma bilirubin concentration was observed when phototherapy and the feeding of charcoal were administered together. The feeding of a $5 \%$ charcoal diet to weanling Gunn rats for 8 wk had no effect on growth rate.
\end{abstract}

The use of oral adsorbents in the management of neonatal hyperbilirubinemia has received little attention in the last few years primarily due to the wide acceptance of phototherapy $(3,9)$; however, a recent review (18) suggested potential mutagenic and/ or carcinogenic long-term side effects with phototherapy. In view of these findings, either an alternative to phototherapy or a reduction in the time and/or intensity of light exposure appears desirable.

Photoisomerization has recently been proposed $(7,11)$ as the predominant mechanism for the biliary excretion of bilirubin during phototherapy. The stable intramolecularly hydrogen bonded $4 Z, 15 Z$ bilirubin - IX $\alpha$ isomer is rapidly and reversibly converted to geometric isomers $(4 \mathrm{Z}, 15 \mathrm{E} ; 4 \mathrm{E}, 15 \mathrm{Z}$; $4 \mathrm{E}, 15 \mathrm{E})$ during phototherapy which have less extensive hydrogen bonding and are readily excreted in the bile. The increased enterohepatic circulation of bilirubin suggested by this mechanism prompted us to compare the effectiveness of phototherapy and activated charcoal for reducing plasma bilirubin levels in the hyperbilirubinemic Gunn rat.

\section{MATERIALS AND METHODS}

Adult female hyperbilirubinemic Gunn rats were fed either Purina lab chow meal or Purina lab chow meal containing $5 \%$ by weight of powdered activated charcoal (Norit SG, Matheson Coleman and Bell Manufacturing Chemists, Norwood, OH). The quantity of charcoal ingested by the rats on the charcoal diet was estimated to be 3-4 g of charcoal per $\mathrm{kg}$ of body weight per $24 \mathrm{~h}$. All rats were fed the regular lab chow meal a few days before each study so they would be accustomed to eating the meal form of the diet. The rats had free access to the diet and tap water during the experimental period.

The light-exposed rats were placed under a bank of eight Westinghouse F40-BB fluorescent lamps for $48 \mathrm{~h}$ at an average irradiance (at the level of the back) of $1.1-1.2 \mathrm{~mW} / \mathrm{cm}^{2}$ in the $400-500 \mathrm{~nm}$ range. The control rats were housed in an animal facility with normal room lighting and exposed to an irradiance of less than $1.0 \mu \mathrm{W} / \mathrm{cm}^{2}$ inside the rat cage. Light measurements were made with a Model 550 Radiometer/Photometer with a multiprobe detector (EGG Inc., Salem, MA) using a $500 \mathrm{~nm}$ cutoff filter (Bausch and Lomb, \#90-1-500, Rochester, NY).

Blood samples were taken from the infraorbital sinus at 0, 24, and $48 \mathrm{~h}$. Plasma bilirubin concentrations were determined by a modification of the Jendrassik and Grof $(5,13)$ procedure.

Eight to ten rats per group were fed either regular meal or the charcoal diet in each of three experiments: experiment a, the rats did not receive phototherapy; experiment $b$, the rats were exposed to intermittent phototherapy ( $12 \mathrm{~h}$ on and $12 \mathrm{~h}$ off) for $48 \mathrm{~h}$; and experiment $\mathrm{c}$, the rats were exposed to continuous phototherapy for $48 \mathrm{~h}$.

Weanling female hyperbilirubinemic Gunn rats (7-8 per group) were fed either Purina lab chow meal or Purina lab chow meal containing 5\% activated charcoal for a period of 8 wk. Body weights were taken weekly and feed consumption was calculated from the feed consumed in a $24-h$ period measured once per wk.

\section{RESULTS}

The mean plasma bilirubin concentrations of the different rat groups at the beginning of the experiments ranged from 6.5-7.6 $\mathrm{mg} / \mathrm{dl}$. The changes in plasma bilirubin were calculated as the \% of the bilirubin values at zero time (Fig. 1).

Plasma bilirubin values were $60 \%$ of the zero values in those rats receiving the charcoal diet for $48 \mathrm{~h}$ (Fig. la). The combination of charcoal feeding and light exposure resulted in a reduction of plasma bilirubin levels to 47 and $39 \%$ of zero values for the intermittent and continuous lighting systems, respectively (Fig. Ib and c).

An irradiance of $1.1-1.2 \mathrm{~mW} / \mathrm{cm}^{2}$ was an effective light dose as demonstrated by a $38 \%$ decrease in plasma bilirubin concentrations in the rats fed regular meal and exposed to continuous phototherapy (Fig. 1c).

The average growth rate for the weanling hyperbilirubinemic female rats was 2.42 and $2.51 \mathrm{~g}$ per day for the rats fed lab chow and lab chow with $5 \%$ activated charcoal, respectively. The average daily consumption of charcoal per rat per $\mathrm{kg}$ of body weight ranged from $4.35 \mathrm{~g}$ in the 11 -wk-old rats to $8.01 \mathrm{~g}$ for the weanling rats.

\section{DISCUSSION}

The use of oral adsorbents to bind bilirubin in the intestinal lumen and prevent its recirculation in the blood has been limited in neonatal hyperbilirubinemic infants. Early reports indicated that orally administered agar was effective in reducing plasma bilirubin levels in both the Gunn rat (14) and the newborn infant (15); however, subsequent findings have failed to confirm its effectiveness in the newborn infant $(16,20)$. Cholestyramine has been shown to decrease plasma bilirubin concentrations in the rat (6) and reduce the exposure time of phototherapy required for hyperbilirubinemic infants (12). Cholestyramine therapy has been associated with constipation and intestinal obstruction (8). Only limited reports $(10,19)$ are available on the use of charcoal as an adsorbent of bilirubin; however, it was reported (19) that terminfants receiving charcoal had lower plasma bilirubin levels than control infants if the administration of charcoal was started within the first four hours of birth. 
(a)

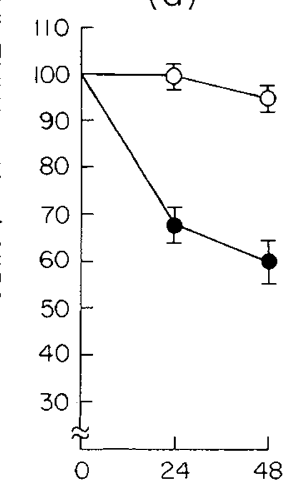

(b)

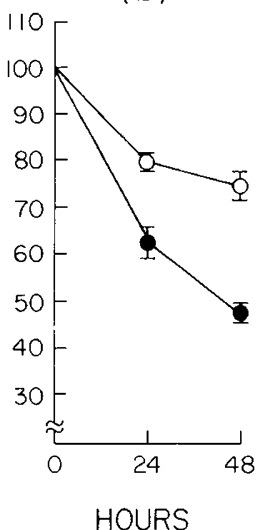

(c)

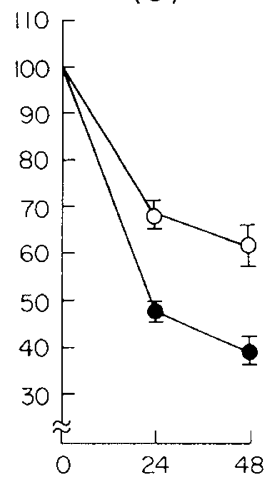

Fig. 1. The effects of charcoal feeding alone and in combination with phototherapy on plasma bilirubin levels in the Gunn rat: $(a)$, no phototherapy; $(b)$, intermittant phototherapy; and $(c)$, continuous phototherapy. Regular lab chow meal $(\mathrm{O}-\mathrm{O})$ and lab chow meal containing 5\% charcoal (-). The vertical lines represent one standard error of the mean (S.E.). Initial mean bilirubin values were $6.5-7.6 \mathrm{mg} / \mathrm{dl}$.

Charcoal was used in this study primarily because of its limited evaluation as an adsorbent of bilirubin and its extensive safe history of use in pediatric medicine for toxic emergencies (2).

The results of this study show that the feeding of activated charcoal to jaundiced female Gunn rats did effectively reduce their plasma bilirubin concentrations. In fact, the feeding of charcoal without phototherapy was just as effective in reducing plasma bilirubin concentrations as continuous phototherapy without charcoal (Fig. la and c). The feeding of charcoal combined with phototherapy did show an additive effect on lowering plasma bilirubin concentrations over and above the effect observed when each treatment was administered separately.

These data suggest that activated charcoal, either alone or in combination with phototherapy, may be a useful therapeutic agent in the management of neonatal hyperbilirubinemia. The use of charcoal may be especially helpful in those situations where a phototherapy unit is not available or in those patients in which phototherapy may not be effective (4). The ability of charcoal alone to decrease plasma bilirubin concentrations suggests a direct transfer of bilirubin across the intestinal mucosa (17) because only a small quantity of bilirubin is excreted in the bile of hyperbilirubinemic Gunn rats (1).

The authors are aware that activated charcoal will bind a broad range of organic and inorganic compounds and that the daily ingestion of charcoal may alter the bioavailability of drugs and essential nutrients. Charcoal treatment would generally be for only a limited period of time. The results of this study indicate that the feeding of charcoal to weanling Gunn rats for up to $8 \mathrm{wk}$ had no effect on growth rate.

The increased biliary output of unconjugated bilirubin during

phototherapy and the binding of bilirubin in the intestinal lumen by adsorbents suggest that the combined use of these treatments may effectively reduce the time and/or intensity of phototherapy routinely used (12). Although charcoal has a safe history of use in pediatric medicine for toxic emergencies, its very limited use in the neonate requires that the safety of this product be further evaluated in neonates.

\section{REFERENCES AND NOTES}

1. Callahan, E. W. and Schmid, R.: Excretion of unconjugated bilirubin in the bile of Gunn rats. Gastroenterology, 57: 134 (1969).

2. Cooney, D. O.: Activated charcoal: antidotal and other medical uses. Drugs and the pharmaceutical sciences, Ed.: J. Swarbrick, Vol. 9, p. 62, (Marcel Dekker, Inc., New York and Basel 1980).

3. Cremer, R. J., Perryman, P. W., and Richards, D. H.: Influence of light on the hyperbilirubinemia of infants. Lancet, $1: 1094$ (1958).

4. Davis, D. R., Yeary, R. A., and Lee, K.: The failure of phototherapy to reduce plasma bilirubin levels in the bile duct-ligated rat. J. Pediatr., 99: 956 (1981).

5. Jendrassik, L. and Grof, P.: Vereinfachte photometrische method zur bestimmung des blulibilirubin. Biochem. Z., 297: 81 (1938).

6. Lester, R., Hammaker, L., and Schmid, R.: A new therapeutic approach to unconjugated hyperbilirubinemia. Lancet, 2: 1257 (1962).

7. Lightner, D. A., Wooldridge. T. A.. and McDonagh, A. F.: Photobilirubin: An early bilirubin photoproduct detected by absorbance difference spectroscopy. Proc. Natl. Acad. Sci., USA, 76: 29 (1979).

8. Lloyd-Still, J.D.: Cholestyramine therapy and intestinal obstruction in infants. Pediatrics, 59: 626 (1977).

9. Lucey, J. Ferreiro, M., and Hewitt, J.: Prevention of hyperbilirubinemia of prematurity by phototherapy. Pediatrics, $41: 1047$ (1968).

10. Luecking, T. and Kuenzer, W.: Adsorption of intestinal bilirubin by carbon. Klin. Wochschr., 44: 469 (1966).

11. McDonagh, A. F., Palma, L. A., and Lightner, D. A.: Blue light and bilirubin excretion. Science, 208: 145 (1980).

12. Nicolopoulos, D., Hadjigeorgiou, E., Malamitsi, A., Kalpoyannis, N., Karli, I., and Papadakis, D.: Combined treatment of neonatal jaundice with cholestyramine and phototherapy. J. Pediatr., 93: 684 (1978).

13. Nosslin, B.: The direct diazo reaction of bile pigments in serum. Scand. J. Clin. Lab. Invest. 12 (Suppl 49): 1 (1960).

14. Odell, G. B., Bolen J. L., Poland, R. L., Seungdamrong, S., and Cukier, J. O.: Protection from nephropathy in jaundiced Gunn rats. Gastroenterology, 66 : 1218 (1974).

15. Poland, R. L. and Odell, M. D.: Physiologic jaundice: The entrohepatic circulation of bilirubin. N. Engl. J. Med., 284: 1 (1971)

6. Romagnoli, C., Polidori, G., Foschini, M., Cataldi, L., DeTurris, P., Tortorolo, G., and Mastrangelo, R.: Agar in the management of hyperbilirubinaemia in the premature baby. Arch. Dis. Child., 50: 202 (1975).

17. Schmid, R. and Hammaker, L.: Metabolism and disposition of $\mathrm{C}^{14}$-bilirubin in congenital nonhemolytic jaundice. J. Clin. Invest., 42: 1720 (1963).

18. Speck, W. T. and Rosenkranz, H. S.: Phototherapy for neonatal hyperbilirubinemia-A potential environmental health hazard to newborn infants. Environ. Mutagen. 1: 321 (1979).

19. Ulstrom, R. A. and Eisenklain, E.: The enterohepatic shunting of bilirubin in the newborn infant. I. Use of oral activated charcoal to reduce normal serum bilirubin values. J. Pediatr., 65: 27 (1964)

20. Windorfer, A., Kunzer, W., Bolze, H., Ascher, K., Wilcken, F., and Hoehne, K Studies on the effect of orally administered agar on the serum bilirubin levels of premature infants and mature newborns. Acta Pediatr. Scand., 64: 699 (1975).

21. This investigation was supported by National Institutes of Health, Grant HD03867.

22. Requests for reprints should be addressed to: Dr. David R. Davis, Department of Veterinary Physiology and Pharmacology, The Ohio State University, 1900 Coffey Road, Columbus, Ohio 43210-1092.

23. Received for publication March 15, 1982

24. Accepted for publication August 16, 1982. 